The Israeli Journal of Aquaculture - Bamidgeh, IJA_72.2020.1207292, 11 pages

CCBY-NC-ND-4.0 • https://doi.org/10.46989/001c.21691

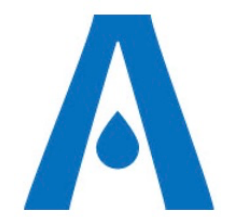

The $I J A$ is a peer-reviewed open-access, electronic journal, freely available without charge to users

Produced by the AquacultureHub non-profit Foundation Sale of IJA papers is strictly forbidden

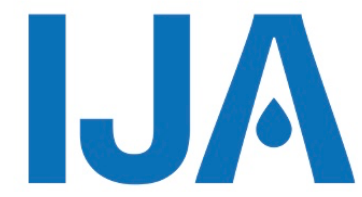

\title{
Aeromonas veronii, a potential pathogen of enteritis in snakehead fish Ophiocephalus argus
}

\author{
Huicong Wang', Ying Gu ${ }^{2,3}$, Guilan Luo', Haipeng Cao ${ }^{2,3 *}$
}

${ }^{1}$ Department of Animal Husbandry \& Veterinary Medicine, Jiangsu Vocational College of Agriculture and Forestry, Jurong Jiangsu 212400, P.R. China.

2 National Pathogen Collection Center for Aquatic Animals, Shanghai Engineering Research Center of Aquaculture, Shanghai Ocean University, Shanghai 201306, P.R. China.

${ }^{3}$ Key Laboratory of Freshwater Fishery Germplasm Resources, Ministry of Agriculture of P. R. China, Shanghai 201306, P.R. China.

Key Words: Aeromonas veronii, Ophiocephalus argus, Enteritis, Potential pathogen

\begin{abstract}
Enteritis is known as a major disease in snakehead fish Ophiocephalus argus aquaculture and has resulted in large economic losses. Yet only scarce information is available on Aeromonas veronii as a causal agent for enteritis in $O$. argus. In this study, a virulent strain, temporarily named $\mathrm{HY} 2$, was isolated from diseased snakehead fish suffering from enteritis, and was identified as $A$. veronii through molecular and phenotypic methods. In addition, the $\mathrm{HY} 2$ isolate showed an $\mathrm{LD}_{50}$ value of $2.8 \times 10^{5} \mathrm{CFU} \mathrm{mL}^{-1}$, and was highly sensitive to aminoglycosides, macrolides, polypeptides, quinolones, sulfonamides and tetracyclines antibiotics. To the best of our knowledge, this is the first report of $A$. veronii as a potential pathogen of enteritis in snakehead fish.
\end{abstract}

* Corresponding author. Tel.: +862161900453, fax: +862161900452, e-mail: hpcao@shou.edu.cn The first two authors contributed equally to this work 


\section{Introduction}

Snakehead fish Ophiocephalus argus is widely cultivated in many countries like China, India, Korea, Malaysia, Philippines and Thailand (Gu et al., 2019). Especially in China, with the rapid development of farming techniques, the snakehead fish has become one of the most important commercial freshwater fish species and has brought a great profit in recent years (Liu et al., 2012). Its production has increased to over 459,000 tons in 2018 (Ministry of Agriculture and Rural Affairs of China, 2019). However, under intensive culture, this industry has been seriously affected by bacterial diseases (Pessoa et al., 2020). Thus, more attention should be given to bacteriosis to make further development of this industry. Enteritis is a major disease in fish aquaculture and usually results in a high mortality (Ying et al., 2020). Several studies have revealed that this disease can be caused by viral, bacterial and parasitic pathogens, including reovirus, Aeromonas punctatus, Aeromonas hydrophila, Pseudomonas putida, Vibrio harveyi, Vibrio cholera, Enteromyxum scophthalmi and Myxidium leei (Wu et al., 2000; Padrós et al., 2001; Zhang et al., 2006; Mao et al., 2010; Carla et al., 2012; Pang et al., 2017; Jiang et al., 2019; Li et al., 2019). Aeromonas veronii is a Gram-negative, rod-shaped, mesophilic, motile bacterium which is ubiquitous in aquatic environments and frequently cause disease outbreaks in warm farming waters (Tekedar et al., 2019). However, little information is available on Aeromonas veronii as a causal agent for enteritis in snakehead fish.

The aim of this study is to characterize the phenotype, taxonomic position and antibiotic susceptibility of $A$. veronii pathogen isolated from enteritis-infected snakehead fish. As far as we know, this is the first report of $A$. veronii as a potential bacterial pathogen of enteritis in snakehead fish, and the findings of this study can be used a reference for health management in snakehead fish.

\section{Snakehead fish samples}

\section{Materials and Methods}

Twenty diseased snakehead fish averaging 550.0 $44.6 \mathrm{~g}$ suffering from enteritis were sampled from a snakehead fish greenhouse farm with a cumulative morbidity of $85 \%$ and water quality parameters of $28^{\circ} \mathrm{C}, \mathrm{pH} 8.20,0.38 \mathrm{mg} \mathrm{L}^{-1}$ of ammonia, $0.13 \mathrm{mg} \mathrm{L}^{-1}$ of nitrite and $0.45 \mathrm{mg} \mathrm{L}^{-1}$ of dissolved oxygen in Sihong, Jiangsu China during October 2019. The snakehead fish were stocked at an initial rearing density of 4 juveniles per square meter and fed commercial feeds at a rate of $3 \%$ of body weight with twice per day. Diseased samples were placed in sterile bags, kept in ice and transported to the laboratory according to Hossain et al. (2020).

\section{Confirmation of the pathogen}

Each sampled diseased snakehead fish was externally disinfected with $75 \%$ alcohol and dissected according to $\mathrm{Li}$ et al. (2011). To verify the potential pathogens, a squash of organs (intestine, liver, kidney, muscle, gill) were made and carefully examined for parasites under the microscope as described by Feng et al. (2019). Meanwhile, virological examination and bacterial infection assay were also conducted. Two hundred and forty experimental healthy fish $(64.7 \pm 1.3 \mathrm{~g})$ were obtained from a snakehead fish farm in Jurong, Jiangsu China, and were acclimated in twenty-four replicate aquaria (ten fish per aquarium) supplied with $100 \mathrm{~L}$ of aerated filtered farming water at $28^{\circ} \mathrm{C}$ for 14 days. Each treatment contained two replicates as recommended by Bela-ong et al. (2015). The virological examination was conducted by injection of bacteria-free organ filtrate from the homogenate of organs according to Perelberg et al. (2003) and Gong et al. (2010). Briefly, the homogenate of organs was made and filtered through $0.22-\mu \mathrm{m}$-pore-size membrane filter to remove bacteria. Two replicate treatment aquaria of ten healthy fish were injected intraperitoneally with $0.2 \mathrm{~mL}$ of each bacteria-free organ filtrate. Another two replicate aquaria of ten healthy fish, which were exposed to the same experimental conditions and injected intraperitoneally with $0.2 \mathrm{~mL}$ of normal saline, served as the control. Experimental fish were kept at $28^{\circ} \mathrm{C}$ without water change. The mortality and any visible changes of the experimental fish were recorded every day for 15 days according to Huang et al. (2013). In addition, $0.1 \mathrm{~g}$ of liver and kidney sample of each diseased fish was cut and streaked 
onto nutrient agar (NA) (Sinopharm Chemical Reagent Co., Ltd.) plates as recommended by Jiang et al. (2019). After incubation for $24 \mathrm{~h}$ at $28^{\circ} \mathrm{C}$, the dominant uniform isolates were purified by streaking and re-streaking onto NA plates. Only the isolates with dense virtually pure culture growth on NA plates were obtained according to Zhang et al. (2017). Induced infection of the pure isolates was performed according to Zhang et al. (2017) and Zhou et al. (2019). Briefly, two replicate treatment aquaria of ten healthy fish were challenged by intraperitoneal injection with $0.2 \mathrm{~mL}$ of each isolate at a concentration of $3.0 \times 10^{5} \mathrm{CFU} \mathrm{mL}^{-1}$ as recommended by Mo et al. (2016), which was determined by counting colony forming units after a ten-fold serial dilution in sterile saline as described by Ma et al. (2009). Another two replicate aquaria of ten healthy fish exposed to the same experimental conditions and injected intraperitoneally $0.2 \mathrm{~mL}$ of normal saline remained unchallenged and served as control. The experimental fish were kept at $28^{\circ} \mathrm{C}$ and observed daily for seven days without feeding and water change. Dead fish were immediately removed to re-isolate and identify the challenge isolate as described above to confirm if the mortality was caused by the challenge isolate. mortality was caused by the challenge isolate.

\section{Identification of the pathogen \\ Molecular identification}

The genomic DNA was extracted from the pathogenic isolate using the TIANamp DNA Kit (Tiangen Biotech. Co., Ltd.). Its 16S rRNA and gyrB genes were amplified by PCR according to Zhu et al. (2017) and were sequenced by ABI 3730 XL DNA Sequencer (Applied Biosystems, USA). A homology search was performed in the National Centre for Biotechnology Information (NCBI) database for $16 \mathrm{~S}$ rRNA and gyrB gene sequences using the Basic Local Alignment Search Tool (BLAST) program. Phylogenetic trees were constructed using neighbour-joining method.

\section{Phenotypic identification}

The pathogenic isolate was observed under transmission electron microscope (HT770, Hitachi, Japan) according to He et al. (2020), and was identified phenotypically by API $20 \mathrm{E}$ system recommended by Zhu et al. (2017), where the pathogenic isolate was grown on NA plates at $28^{\circ} \mathrm{C}$ for $24 \mathrm{~h}$, and the bacterial suspension was then used to inoculate the API $20 \mathrm{E}$ test strips (Biomerieux, France) following the manufacturer's instruction. The plate was incubated at $37^{\circ} \mathrm{C}$ and observed after $18 \mathrm{~h}$ for checking against the API identification index and database. Information related to $A$. veronii previously reported by Dong \& Cai (2001) and Yang et al. (2013) serves as a reference.

\section{Bacterial virulence assay}

Bacterial virulence assay was carried out by experimentally infecting healthy snakehead fish and was conducted in strict accordance with the Regulations on Experimental Animals Administration of China (Publication No. 676). One hundred healthy snakehead fish averaging $65.5 \pm 1.1 \mathrm{~g}$ were obtained from a snakehead fish farm in Jurong, Jiangsu China. The experimental fish were acclimated in ten replicate aquaria (ten fish per aquarium) supplied with $100 \mathrm{~L}$ of aerated filtered farming water at $28^{\circ} \mathrm{C}$ for 14 days. Each treatment contained two replicates as recommended by Bela-ong et al. (2015). Prior to the bacterial virulence assay the suspension of the pathogenic isolate was prepared according to Zhang et al. (2017) and its cell density was determined by counting colony forming units after a ten-fold serial dilution in sterile saline as described by $\mathrm{Ma}$ et al. (2009). Two replicate aquaria of ten healthy fish were challenged by intraperitoneal injection (Mo et al., 2016)

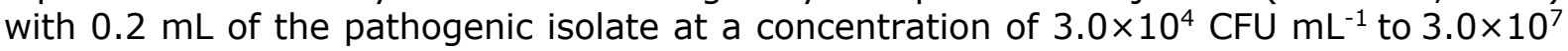
CFU $\mathrm{mL}^{-1}$. Another two replicate aquaria of ten healthy fish exposed to the same experimental conditions and injected intraperitoneally $0.2 \mathrm{~mL}$ of normal saline remained unchallenged and served as control. The experimental fish were kept at $28^{\circ} \mathrm{C}$ and were observed daily for seven days without feeding and water change. Any dead fish were immediately removed and sampled to re-isolate and confirm if the mortality was caused specifically by the challenge isolate according to Kozińska et al. (2002). Briefly, dead fish 
were sampled to re-isolate the challenge isolate which was confirmed phenotypically and molecularly as described above. The mean lethal dose (LD $\left.{ }_{50}\right)$ value is calculated using the linear regression method as recommended by Spielmann et al. (1999).

\section{Antibiotic susceptibility assay}

The antibiotic susceptibility of the pathogenic isolate was examined on NA plates using the Kirby-Bauer disk diffusion method as recommended by Fang et al. (2019). Fourteen antibiotic discs were provided by Hangzhou Binhe Microorganism Reagent Co., Ltd.. The zones of inhibition against the pathogenic isolate were measured after a $24 \mathrm{~h}$ incubation period at $28^{\circ} \mathrm{C}$, and its susceptibility to antibiotics was assessed according to the manufacturer's guidelines.

\section{Identification of the pathogen}

\section{Results}

No parasites were found in the diseased snakehead fish, and all of the experimental fish challenged with the bacteria-free organ filtrate survived with no visible changes (data not shown), indicating that this disease was not caused by parasites or viruses. A total of five dominant isolates (temporarily numbered from HY1 to HY5) were recovered from diseased fish, and only isolate HY2, which could be isolated from liver and kidney of all the sampled fish, was confirmed as the pathogen for this disease according to Koch's postulate: (i) The HY2 isolate could be isolated from diseased snakehead fish. (ii) The death of the experimental fish was increased gradually over time after the challenge with isolate HY2. $25 \%-100 \%$ of the challenged fish died at an LD 50 value of $2.8 \times 10^{5} \mathrm{CFU} \mathrm{mL}^{-1}$ (Table 1) and exhibited enteritis signs similar to that seen in the originally diseased fish (Figure 1). No clinical signs or mortality were noted in the control fish. (iii) The HY2 isolate could be re-isolated from experimentally dead fish, which was determined through phenotypic and molecular identification. These findings demonstrated that isolate HY2 was the causative agent of this disease.

Table 1. Cumulative mortality of experimental snakehead fish infected by isolate HY2.

\begin{tabular}{|c|c|c|c|c|c|c|c|c|c|c|c|}
\hline \multirow{2}{*}{ Group } & \multirow{2}{*}{$\begin{array}{l}\text { Concentration } \\
\left.\text { (CFU mL } \mathrm{mL}^{-1}\right)\end{array}$} & \multirow{2}{*}{$\begin{array}{l}\text { Fish } \\
\text { no. }\end{array}$} & \multicolumn{7}{|c|}{$\begin{array}{l}\text { Dead fish no. on day } \\
\text { after challenge }\end{array}$} & \multirow{2}{*}{$\begin{array}{c}\text { Average } \\
\text { cumulative } \\
\text { mortality } \\
(\%)\end{array}$} & \multirow{2}{*}{$\begin{array}{l}\text { LD }_{50} \text { value } \\
\left(C F U \mathrm{~mL}^{-1}\right)\end{array}$} \\
\hline & & & 1 & 2 & 3 & 4 & 5 & 6 & 7 & & \\
\hline \multirow{2}{*}{ Control } & \multirow{2}{*}{0} & 10 & 0 & 0 & 0 & 0 & 0 & 0 & 0 & \multirow{2}{*}{0} & \multirow{10}{*}{$2.8 \times 10^{5}$} \\
\hline & & 10 & 0 & 0 & 0 & 0 & 0 & 0 & 0 & & \\
\hline \multirow{2}{*}{ Treatment 1} & \multirow{2}{*}{$3.0 \times 10^{4}$} & 10 & 0 & 2 & 0 & 0 & 0 & 0 & 0 & \multirow{2}{*}{25} & \\
\hline & & 10 & 1 & 1 & 1 & 0 & 0 & 0 & 0 & & \\
\hline \multirow{2}{*}{ Treatment 2} & \multirow{2}{*}{$3.0 \times 10^{5}$} & 10 & 2 & 1 & 0 & 1 & 0 & 0 & 0 & \multirow{2}{*}{40} & \\
\hline & & 10 & 1 & 1 & 1 & 0 & 1 & 0 & 0 & & \\
\hline \multirow{2}{*}{ Treatment 3} & \multirow{2}{*}{$3.0 \times 10^{6}$} & 10 & 2 & 3 & 1 & 1 & 0 & 1 & 0 & \multirow{2}{*}{85} & \\
\hline & & 10 & 3 & 1 & 2 & 2 & 0 & 1 & 0 & & \\
\hline \multirow{2}{*}{ Treatment 4} & \multirow{2}{*}{$3.0 \times 10^{7}$} & 10 & 5 & 3 & 2 & 0 & 0 & 0 & 0 & \multirow{2}{*}{100} & \\
\hline & & 10 & 8 & 1 & 1 & 0 & 0 & 0 & 0 & & \\
\hline
\end{tabular}




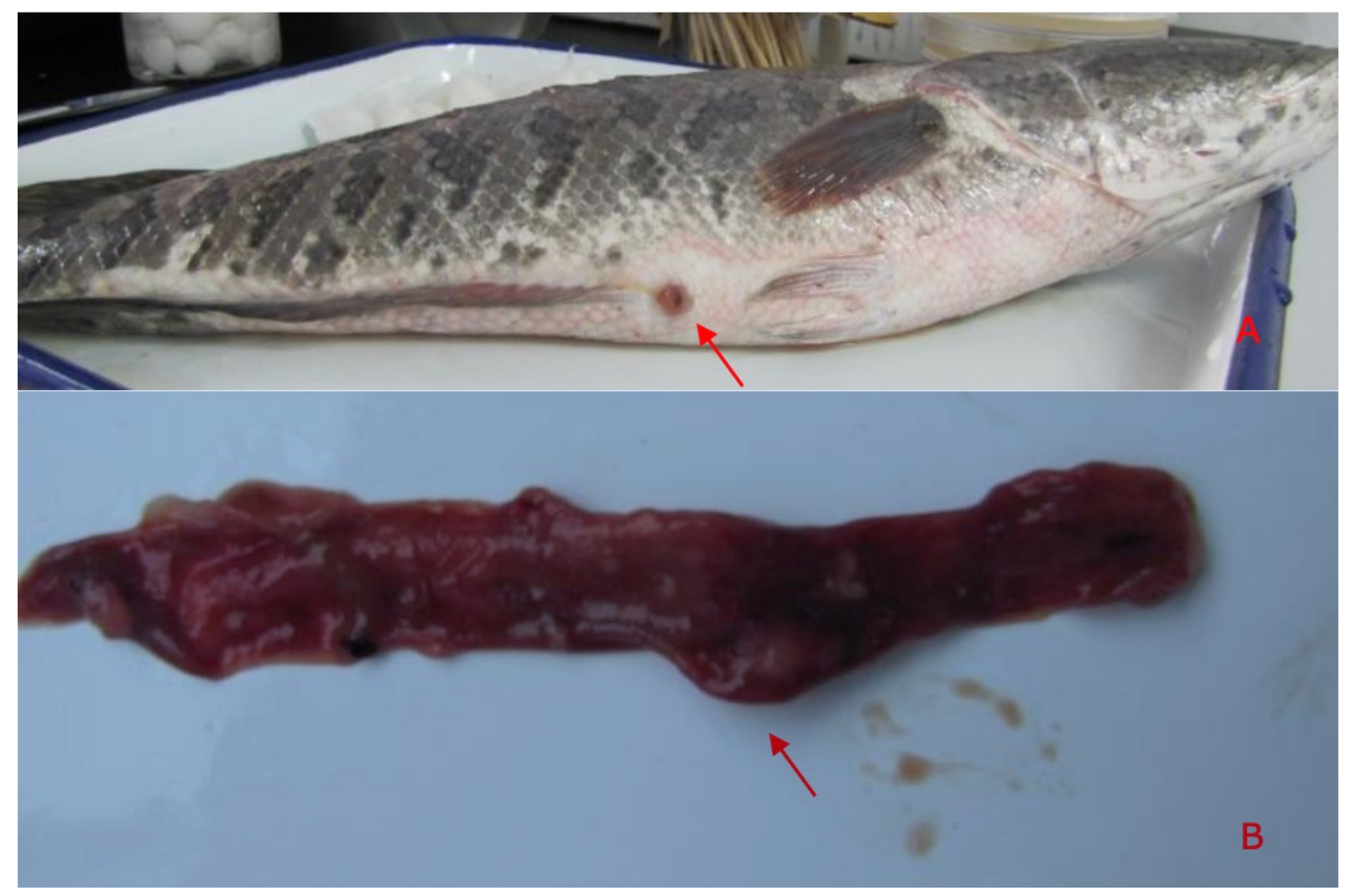

Figure 2. Transmission electron microscopy image of isolate HY2. Arrow shows the rod-shaped cell.

Identification of the pathogen

Isolate HY2 was rod-shaped (Figure 2). Its near complete 16S rRNA and gyrB gene sequences were submitted to GenBank database with the accession nos. MT875223 and MT894140. The phylogenetic trees (Figures 3 and 4) indicate that the HY2 isolate is identified as an $A$. veronii strain. Besides, isolate HY2 was also confirmed by the phenotypic features (Table 2 ) as $A$. veronii with $100 \%$ identity compared to the reference strain. Thus, isolate HY2 was identified as A. veronii. 


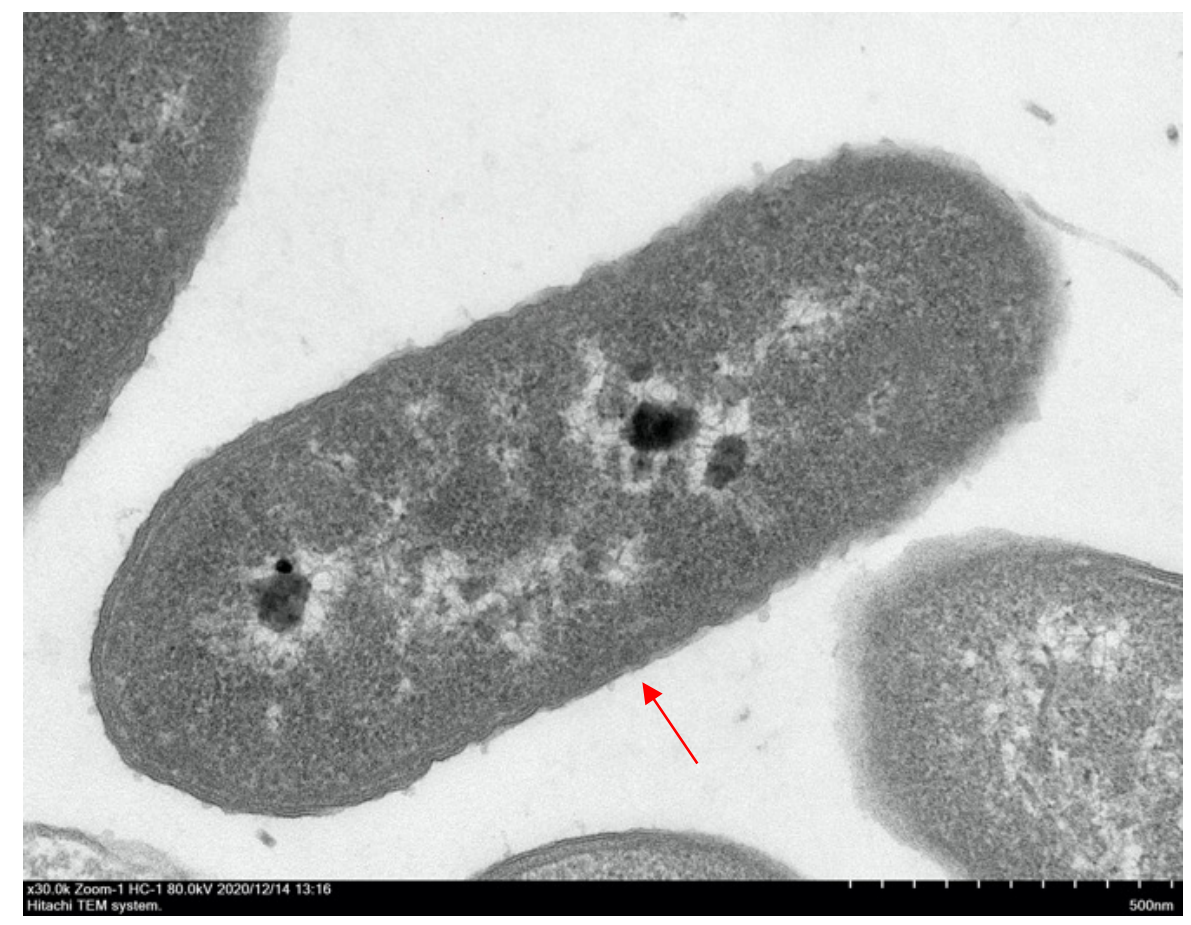

Figure 2. Transmission electron microscopy image of isolate HY2. Arrow shows the rod-shaped cell.

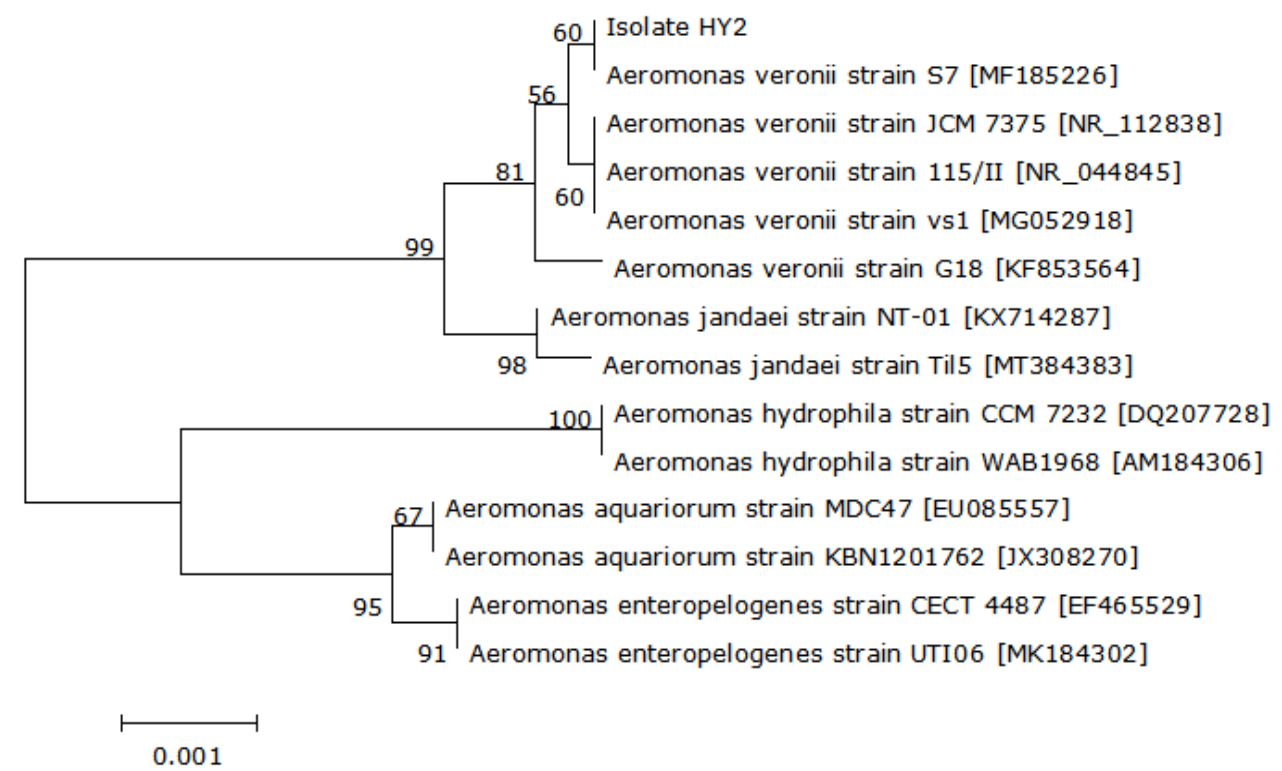

Figure 3. A $16 \mathrm{~S}$ rRNA gene tree of 13 known bacteria and the HY2 isolate constructed using the neighbor-joining method. The bootstrap values (\%) are shown besides the clades, accession numbers are indicated beside the names of strains, and scale bars represent distance values. 


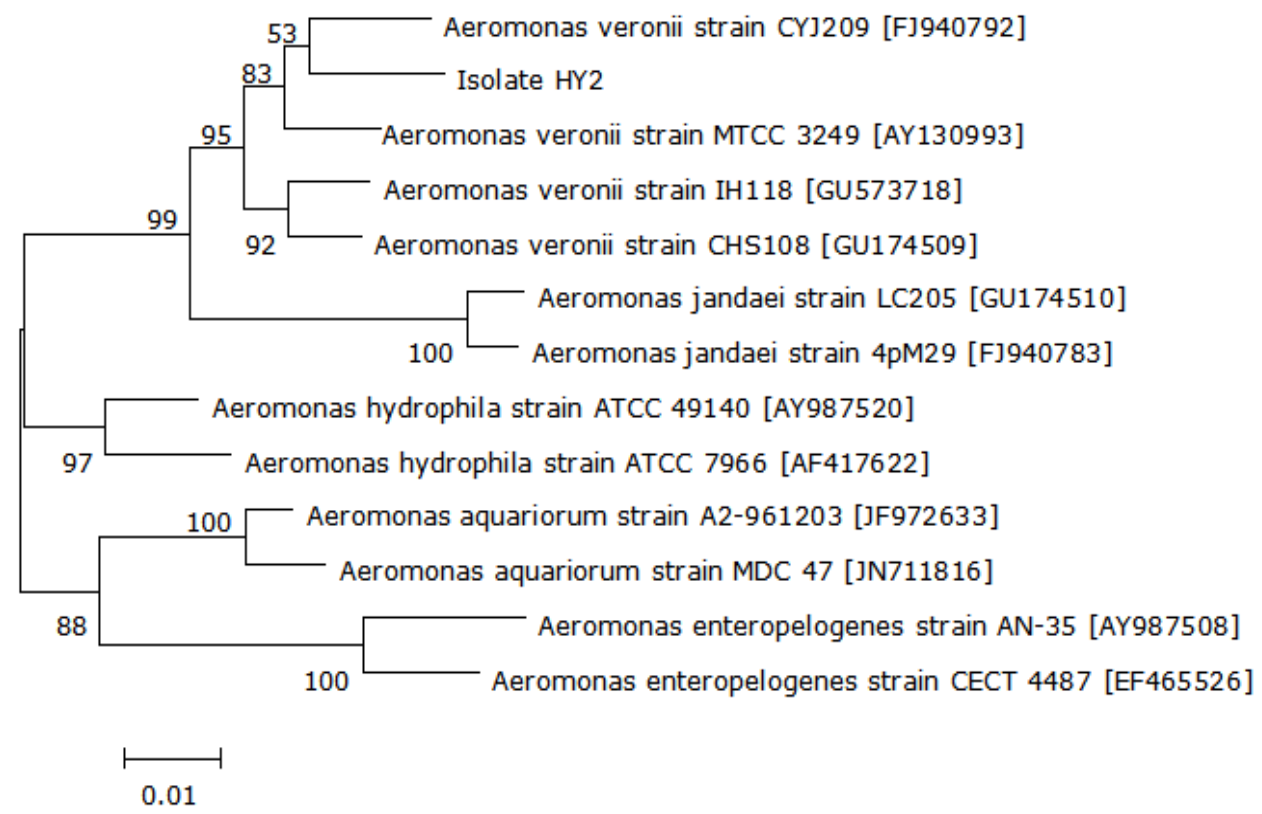

Figure 4. A gyrB gene tree of 12 known bacteria and the HY2 isolate constructed using the neighbor-joining method. The bootstrap values (\%) are shown besides the clades, accession numbers are indicated beside the names of strains, and scale bars represent distance values.

Antibiotic susceptibility of the pathogen

The antibiotic susceptibility of isolate HY2 is shown in Table 3. The data indicate that isolate HY2 is sensitive to amikacin, cotrimoxazole, enrofloxacin, gentamicin, kanamycin, levofloxacin, midecamycin, norfloxacin, ofloxacin, polymyxin B, streptomycin, tetracycline, vancomycin, and exhibit resistance to ampicillin. This suggests that isolate HY2 can be potentially controlled by aminoglycosides, macrolides, polypeptides, quinolones, sulfonamides, tetracyclines antibiotics.

Table 3. Susceptibility of isolate HY2 to antibiotics.

\begin{tabular}{ccc}
\hline Antibiotics & Content $(\boldsymbol{\mu g} / \mathbf{d i s c})$ & Inhibition zone diameter $(\mathbf{m m})$ \\
\hline Amikacin & 30 & $23.59 \pm 3.36^{\mathrm{S}}$ \\
Ampicillin & 10 & $0 \pm 0^{\mathrm{R}}$ \\
Cotrimoxazole $^{*}$ & $1.25 / 23.75$ & $25.61 \pm 2.18^{\mathrm{S}}$ \\
Enrofloxacin $^{*}$ & 5 & $31.23 \pm 1.26^{\mathrm{S}}$ \\
Gentamycin $^{\mathrm{s}}$ & 10 & $20.76 \pm 0.76^{\mathrm{S}}$ \\
Kanamycin & 30 & $20.88 \pm 2.28^{\mathrm{S}}$ \\
Levofloxacin & 5 & $33.49 \pm 1.07^{\mathrm{S}}$ \\
Midecamycin & 30 & $13.88 \pm 1.43^{\mathrm{S}}$ \\
Norfloxacin & 10 & $31.41 \pm 1.02^{\mathrm{S}}$ \\
Ofloxacin $_{\text {Polymyxin B }}$ & 5 & $30.88 \pm 2.77^{\mathrm{S}}$ \\
Streptomycin & 300 & $12.44 \pm 1.39^{\mathrm{S}}$ \\
Tetracycline $^{*}$ & 10 & $21.20 \pm 1.89^{\mathrm{S}}$ \\
Vancomycin & 30 & $21.19 \pm 0.81^{\mathrm{S}}$ \\
\hline
\end{tabular}

Data are presented as the mean \pm standard deviation. SSensitive; ${ }^{R}$ Resistant.

*Antibiotics for aquaculture use (Ministry of Agriculture of China, 2013). 


\section{Discussion}

Aeromonas species are dominant flora in fish aquaculture (Zhang et al., 2006; Wang et al., 2020), and are also major bacterial fish pathogens (Lazado et al., 2018). For example, Ying et al. (2020) proved a dominant virulent isolate of $A$. punctata as the pathogen of enteritis in Symphysodon aequifasciatus. Yang et al. (2007) confirmed a dominant virulent isolate of Aeromonas salmonicida as the pathogen of skin ulceration disease in Apostichopus japonicus. In the present study, the dominant isolate HY2 was found to show

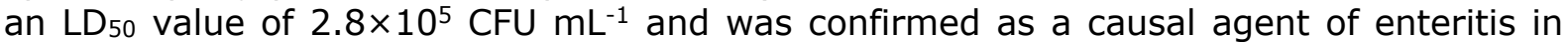
snakehead fish, further indicating that the dominant pathogenic isolate is probably the causal agent of fish diseases. To our knowledge, this is the first report of an $A$. veronii pathogen of enteritis in snakehead fish.

A. veronii is widely distributed in aquatic ecosystems and possesses a variety of virulence factors, including aerolysin, cytotoxic enterotoxins, DNases, elastase, hemolysins, leucocidins, lipases, outer membrane proteins, proteases (Chen et al., 2019; Li et al., 2020). The association of $A$. veronii in aquaculture has been well documented with mortality of Coregonus clupeaformis (Loch et al., 2010), Astronotus ocellatus (Sreedharan et al., 2011), Leiocassis longirostris Günther (Cai et al., 2012), Dicentrarchus labrax (Uzun et al., 2015), Cyprinus carpio (Sun et al., 2016), Oreochromis niloticus (Hassan et al., 2017), Carassius auratus gibelio (Chen et al., 2019), Eriocheir sinensis (Zhou et al., 2019), Ictalurus punctatus (Tekedar et al., 2020), Colossoma macropomum (Pessoa et al., 2020), Procambarus clarkii (Hu et al., 2020) and Neophocaena phocaenoides asiaeorientalis (Liu et al., 2020). In our study, $A$. veronii isolate HY2 was demonstrated to cause mortality in snakehead fish, further revealing its potential threat to fish farming. Apart from the virulence of the HY2 isolate, there might be other secondary factors that induce enteritis in snakehead fish such as poor water quality, temperature changes and over intensification of stocking density (Zhu et al., 2020; Zhou et al., 2020); these should also be raised as concerns.

The development of antimicrobial resistance in $A$. veronii is a matter of concern (Tekedar et al., 2020). In our study, the HY2 isolate developed resistance to ampicillin. The same resistance has been observed in the pathogenic $A$. veronii isolated from diseased $C$. auratus gibelio, O. niloticus and I. punctatus (Xia et al., 2012; Hassan et al., 2017; Tekedar et al., 2020). The HY2 isolate in our study has exhibited sensitivity to aminoglycosides, quinolones, tetracyclines and sulfonamides drugs used in fish farming regions, suggesting that the outbreak of this disease may not have resulted from the abuse of antibiotics.

In conclusion, the present study for the first time reports an $A$. veronii isolate as a potential pathogen of enteritis in $O$. argus. The pathogenicity of the HY2 isolate supports this infection as a potential threat in snakehead fish farming.

\section{Acknowledgments}

This work has been financially supported by Earmarked Fund for Sci-Tech Fund of Jiangsu Vocational College of Agriculture and Forestry (No. 2020kj060) and Jiangsu Modern Agricultural Industry Technology System (JATS [2019] 391).

\section{References}

Bela-ong D.B., Schyth B.D., Zou J., Secombes C.J. and N. Lorenzen, 2015. Involvement of two microRNAs in the early immune response to DNA vaccination against a fish rhabdovirus. Vaccine, 33(28): 3215-3222. DOI:10.1016/j.vaccine.2015.04.092

Carla P., Natalia M., Iris M., Jacobo F., Manuel L.S., Jesús L. and M.L. José, 2012. Development of a real-time PCR assay for detection and quantification of Enteromyxum scophthalmi parasites in turbot intestinal samples. Aquaculture, 366-367: 122-128. DOI: 10.1016/j.aquaculture.2012.09.008

Cai S., Wu Z., Jian J., Lu Y. and J. Tang, 2012. Characterization of pathogenic Aeromonas veronii bv. veronii associated with ulcerative syndrome from chinese longsnout catfish (Leiocassis longirostris Günther). Brazilian journal of microbiology, 43(1): 382-388. DOI: $10.1590 / S 1517-83822012000100046$ 
Chen F., Sun J., Han Z., Yang X., Xian J., Lv A., Hu X. and H. Shi, 2019. Isolation, identification and characteristics of Aeromonas veronii from diseased crucian carp (Carassius auratus gibelio). Frontiers in Microbiology, 10: 2742. DOI: 10.3389/fmicb.2019.02742

Dong X.Z., Cai M.Y., 2001. General manual of systematic and determinative bacteriology. Science Press, Beijing, 117pp.

Fang Z., Zeng Y., Hong M. and L. Ding, 2019. Identification and susceptibility test of pathogenic Aeromonas veronii isolated from Mauremys sinensis. China Animal Husbandry \& Veterinary Medicine, 46(9): 2760-2768. DOI: 10.16431/j.cnki.1671-7236.2019.09.032

Feng Y., Duan J., Huang X., Wang K., Deng Y., Geng Y., Ouyang P. and D. Chen, 2019. Pathological study on fulminant hemorrhagic ulcer syndrome of Ictalurus punctatus. Journal of South China Agricultural University, 40(1): 65-71. DOI: $10.7671 / j$. issn.1001-411X.201804013

Gong Q., Gao S., Shan X., Guo W., Meng Q., Wang W. and A. Qian., 2010. Isolation and identification of pathogenic Aeromonas veronii from Cyprinus carpio. Chinese Journal of Preventive Veterinary Medicine, 32(12): 981-983. DOI: $10.3969 / \mathrm{j}$. issn.10080589.2010 .12 .18

Gu Y., Wang H., Guo C., Chen J. and H. Cao, 2019. Citrobacter freundii: a causative agent for ulcer disease in snakehead fish Ophiocephalus argus (Cantor). Israeli Journal of Aquaculture-Bamidgeh, 71: 1613.

Hassan M.A., Noureldin E.A., Mahmoud M.A. and N.A. Fita, 2017. Molecular identification and epizootiology of Aeromonas veronii infection among farmed Oreochromis niloticus in Eastern Province, KSA. Egyptian Journal of Aquatic Research, 43(2): 161-167. DOI: $10.1016 /$ j.ejar.2017.06.001

He S., Wei W., Liu T., Yang Q., Xie H., He Q. and K. Wang, 2020. Isolation, identification and histopathological study on lethal sarcoidosis of Micropterus salmoides. Journal of Fisheries of China, 44(2): 253-265. DOI: $10.11964 / j f c .20181011495$

Hossain S., De Silva B.C.J., Dahanayake P.S., De Zoysa M. and G.J. Heo, 2020. Phylogenetic characteristics, virulence properties and antibiogram profle of motile Aeromonas spp. isolated from ornamental guppy (Poecilia reticulata). Archives of Microbiology, 202(3): 501-509. DOI: https://doi.org/10.1007/s00203-019-01762-5

Hu Q., Hu R., Jin Y. and Z. Gu, 2020. Isolation, identification and pathohistological observation of Aeromonas veronii from Procambarus clarkii. Acta Hydrobiologica Sinica, 44(4): 811-818. DOI: $10.7541 / 2020.097$

Huang J., Huang Y., Hu D., Luo H., Shi J., Peng M., Xuan J., Tan L., Teng Z. and K. Zeng, 2013. Characterization of white plastron disease pathogens and detection of six known virulence genes in Truogx sinensis. Acta Hydrobiologica Sinica, 5: 844-854. DOI: $10.7541 / 2013.108$

Jiang G., Deng S., Zou L., Cheng X., Li C. and L. Liu, 2019. Identification of a bacterial pathogen isolated from Sinilabeo decorus tungting with acute bacterial enteritis and its histopathology observations. Chinese Journal of Preventive Veterinary Medicine, 41(9): 906-910. DOI: $10.3969 / j$.issn.1008-0589.201903021

Kozińska A., Figueras M.J., Chacon M.R., and L. Soler, 2002. Phenotypic characteristics and pathogenicity of Aeromonas genomospecies isolated from common carp (Cyprinus carpio L.). Journal of Applied Microbiology, 93(6): 1034-1041. DOI: 10.1046/j.1365-2672.2002.01784.x

Lazado C.C. and D. Zilberg, 2018. Pathogenic characteristics of Aeromonas veronii isolated from the liver of a diseased guppy (Poecilia reticulata). Letters in Applied Microbiology, 67(5): 476-483. DOI: 10.1111/lam.13057

Li W., Li X., Rao L., Huang J., Yu Y., Xiao F. and Q. Yan, 2019. Effects of reovirus Infection on the intestinal microbiota diversity of grass carp (Ctenopharyngodon idella). Acta Hydrobiologica Sinica, 43(1): 109-116. DOI: 10.7541/2019.014

Li T., Raza S.H.A., Yang B., Sun Y., Wang G., Sun W., Qian A., Wang C., Kang Y. and $\mathbf{X}$. Shan, 2020. Aeromonas veronii infection in commercial freshwater fish: A potential threat to public health. Animals, 10(4): 608-618. DOI: 10.3390/ani10040608 
Li J., Ye X., Lu M., Deng G., Chi Y. and Z. Huang, 2011. Isolation and identification of Aeromonas veronii from infected tilapia fry and analysis of its drug sensitivity. Journal of Hydroecology, 32(3): 132-136. DOI: 10.15928/j.1674-3075.2011.03.027

Liu J. and A. Li, 2012. First case of Aeromonas schubertii infection in the freshwater cultured snakehead fish, Ophiocephalus argus (Cantor), in China. Journal of Fish Diseases, 35(5): 1-8. DOI: 10.1111/j.1365-2761.2012.01350.x

Liu Z., Li A., Wang Y., Iqbal M., Zheng A., Zhao M., Li Z., Wang N., Wu C. and D. Yu, 2020. Comparative analysis of microbial community structure between healthy and Aeromonas veronii-infected Yangtze fnless porpoise. Microbial Cell Factories, 19(1): 123. DOI: $10.1186 / \mathrm{s} 12934-020-01383-4$

Loch T.P. and M. Faisal, 2010. Infection of lake whitefish (Coregonus clupeaformis) with motile Aeromonas spp. in the Laurentian great lakes. Journal of Great Lakes Research, 36: 6-12. DOI: 10.1016/j.jglr.2009.07.001

Ma Z., Yang H., Li T., Luo L. and J. Gao, 2009. Isolation and identification of pathogenic Aeromonas veronii isolated from infected Siberian sturgeon (Acipenser baerii). Acta Microbiologica Sinica, 49(10): 1289-1294. DOI: 10.13343/j.cnki.wsxb.2009.10.018

Mao Z., Wang M., Chen J. and J. Yang, 2010. Isolation and characterization of Pseudomonas putida, a causative agent of gastroenteritis in black sea bream, Sparus macrocephalus. Progress in Fishery Sciences, 31(3): 23-28. DOI: 10.3969/j.issn.10007075.2010.03.004

Ministry of Agriculture and Rural Affairs of China, 2019. China Fishery Statistical Yearbook. China Agriculture Press, Beijing. 25 pp.

Ministry of Agriculture of China, 2013. The First Catalogue of Veterinary Prescription Drugs. China Animal Health, 15(11): 81-83.

Mo J., Jiang L. and Z. Wu, 2016. Biological characteristics and drug susceptibility of Aeromonas schubertii WL-4 isolated from snakehead. Journal of Fisheries of China, 40(3): 484-494. DOI: $10.11964 /$ jfc.20160110250

Pang H., Liao M., Li B., Rong X., Wang Y., Zhang Z., Sun J. and F. Meng, 2017. Etiology and treatment of enteritis disease in cultured junviles of Apostichopus japonicus. Progress in Fishery Sciences, 38(3): 188-197. DOI: 10.11758/yykxjz.20160720002

Padrós F., Palenzuela O., Hispano C., Tosas O., Zarza C., Crespo S. and P. AlvarezPellitero, 2001. Myxidium leei (Myxozoa) infections in aquarium-reared Mediterranean fish species. Diseases of Aquatic Organisms, 47(1): 57-62. DOI: 10.3354/dao047057

Pessoa R.B.G., Marques D.S.C., Lima R.O.H.A., Oliveira M.B.M., Lima G.M.S., Maciel de Carvalho E.V.M. and L.C.B.B. Coelho, 2020. Molecular characterization and evaluation of virulence traits of Aeromonas spp. isolated from the tambaqui fish (Colossoma macropomum). Microbial Pathogenesis, 147: 104273. DOI: 10.1016/j.micpath.2020.104273

Perelberg A., Smirnov M., Hutorian M., Diamant A., Bejerano Y. and M. Kotler, 2003. Epidemilogical description of a new viral disease afflicting cultured Cyprinus Carpio in Israel. The Israeli journal of aquaculture-Bamidgeh, 55(1): 5-12.

Spielmann H., Genschow E., Liebsch M. and W. Halle, 1999. Determination of the starting dose for acute oral toxicity $\left(\mathrm{LD}_{50}\right)$ testing in the up and down procedure (UDP) from cytotoxicity data. Alternatives to Laboratory Animals, 27: 957-966. DOI: 10.1177/026119299902700609

Sreedharan K., Philip R. and I.S. Singh, 2011. Isolation and characterization of virulent Aeromonas veronii from ascitic fluid of oscar Astronotus ocellatus showing signs of infectious dropsy. Diseases of Aquatic Organisms, 94(1): 29-39. DOI: 10.3354/dao02304

Sun J., Zhang X., Gao X., Jiang Q., Wen Y. and L. Lin, 2016. Characterization of virulence properties of Aeromonas veronii isolated from diseased gibel carp (Carassius gibelio). International Journal of Molecular Sciences, 17(4): 496. DOI: $10.3390 /$ ijms 17040496

Tekedar H.C., Arick M.A., Hsu C.Y., Thrash A., Blom J., Lawrence M.L., and H. Abdelhamed, 2020. Identification of antimicrobial resistance determinants in Aeromonas veronii Strain MS-17-88 recovered from channel catfish (Ictalurus punctatus). Frontiers in Cellular and Infection Microbiology, 10: 348. DOI: 10.3389/fcimb.2020.00348 
Tekedar H.C., Kumru S., Blom J., Perkins A.D., Griffin M.J., Abdelhamed H., Karsi A. and M.L. Lawrence, 2019. Comparative genomics of Aeromonas veronii: Identification of a pathotype impacting aquaculture globally. PLOS ONE, 14(8): 1-25. DOI: 10.1371 journal.pone. 0221018

Uzun E. and H. Ogut, 2015. The isolation frequency of bacterial pathogens from sea bass (Dicentrarchus labrax) in the Southeastern Black Sea. Aquaculture, 437(1): 30-37. DOI: 10.1016/j.aquaculture.2014.11.017

Wang M., Zhang X., Du W., Yu X., Liu B., Wu T., Shi Q. and Z. Zhang, 2020. Isolation, identification and drug sensitivity test of a strain of Aeromonas veronii from Chinemys reevesii. Chinese Journal of Animal and Veterinary Sciences, 51(10): 2528-2535. DOI: $10.11843 / \mathrm{j}$.issn.0366-6964.2020.10.021

Wu L., Zhang D., Wang G. and Z. Sun, 2000. The main diseases and prevention and treatment of Ictalurus punctatus. Freshwater Fisheries, 30(10): 35-37. DOI: CNKI:SUN:DSYY.0.2000-10-026

Xia F., Liang L. and J. Xie, 2012. Isolation, identification and susceptibility test of the pathogenic Aeromonas veronii from Carassius auratus gibelio. Freshwater Fisheries, 42(5): 22-26. DOI: $10.3969 / j$.issn.1000-6907.2012.05.005

Yang X., 2013. Isolation, identification and susceptibility test of the pathogenic Aeromonas Veronii from goldfish (Carassius auratus). Modern Agricultural Science and Technology, 2013(6): 256-258. DOI: 10.3969/j.issn.1007-5739.2013.06.162

Yang J., Zhou L., Xing J., Sheng X., and W. Zhan, 2007. Identification of Aeromonas salmonicida associated with skin ulceration of cultured sea cucumber Apostichopus japonicus and characterization of the extracellular products. Journal of Fishery Sciences of China, 14(6): 981-989. DOI: 10.3321/j.issn:1005-8737.2007.06.014

Ying N., Wang Y., Qin B., Wu Y., Song X., Yang L., Gao W., Qin Z. and W. Fang, 2020. Isolation, identification and antimicrobial susceptibility of Aeromonas punctata from Symphysodon aequifasciatus. Fisheries Science \& Technology Information, 47(5): 245248. DOI: $10.16446 /$ j.fsti.20200100129

Zhang X., Cui W., Ding S., Li W. and Q. Zhang, 2017. Isolation, identification and antibiotic sensitivity of Aeromonas veronii from Litopenaeus vannamei. Microbiology China, 44(12): 2795-2804. DOI: 10.13344/j.microbiol.china.170550

Zhang X., Chen C. and H. Fang, 2006. Biological characterization and phylogenetic analysis of Aeromonas hydrophila from grass carp Ctenophar yngodon idellus. Chinese Journal of Zoonoses, 22(4): 334-337. DOI: 10.3969/j.issn.1002-2694. 2006.04.012

Zhou H., Huang X., An J., Cao H. and X. Yang, 2019. Isolation, identification and antibiotic susceptibility of pathogenic Aeromonas veronii in Eriocheir sinensis and its histopathological observations. Journal of Southern Agriculture, 50(8): 1851-1859. DOI: CNKI:SUN: GXNY.0.2019-08-029

Zhou A., Xie S., Sun D., Liu S., Zhang C., Sun Z., Zhang Y., Chen Y. and J. Zou, 2020. Expression of HSP70 family mRNAs in albino northern snakehead, Channa argus: Response to extreme temperature stress and bacterial infection. Fish \& Shellfish Immunology, 104: 457-469. DOI: 10.1016/j.fsi.2020.05.033

Zhu N., Bei Y., Zheng X., Liang Q., Cao F. and X. Ding, 2020. Evaluation of drugresistant phenotypes and genes of Aeromonas spp. isolated from Channa argus. Fisheries Science \& Technology Information, 47(3): 145-149. DOI: 10.16446/j.fsti.20190900304

Zhu C., Liu G., Zhang Z., Pu D., Zhu L., Zhou C., Lei L. and Z. Zheng, 2017. Identification of a pathogenic Aeromonas veronii isolated from rock carp, Procypris rabaudi. Chinese Journal of Zoonoses, 33(6): 526-534. DOI: 10.3969/j.issn.10022694.2017.06.011 